\title{
Highlights of Analytical Sciences in Switzerland
}

Division of Analytical Sciences

\section{Using Isotopic Fingerprints to Trace Nitrous Oxide in the Atmosphere}

\section{Eliza Harris*a, Lukas Emmenegger, and Joachim Mohn* \\ ${ }^{*}$ Correspondence: Dr. E. Harrisa, Dr. J. Mohn, Laboratory of Air Pollution Environmental Technology, Empa Dübendorf, Überlandstrasse 129, CH-8600 Dübendorf, E-Mail: Eliza.Harris@uibk.ac.at, Joachim.Mohn@empa.ch. aPresent address: Plant, Soil and Ecosystems Processes Research Group, Institute for Ecology, University of Innsbruck, Steinwartstr. 15, A-6020 Innsbruck}

Keywords: Greenhouse gas · Isotope · Nitrous oxide · Spectroscopy

Nitrous oxide $\left(\mathrm{N}_{2} \mathrm{O}\right)$ is an important greenhouse gas and a dominant contributor to stratospheric ozone destruction. Anthropogenic $\mathrm{N}_{2} \mathrm{O}$ emissions arise from a range of activities, in particular, agriculture, fertilizer use, wastewater treatment, and energy production. The variability and partitioning of $\mathrm{N}_{2} \mathrm{O}$ emissions between different source types is poorly understood, making it difficult to develop policies to efficiently reduce emissions.

Isotopic composition of $\mathrm{N}_{2} \mathrm{O}$ is a tracer to distinguish between different emission processes and pathways, as well as constraining the stratospheric $\mathrm{N}_{2} \mathrm{O}$ sink. $\mathrm{N}_{2} \mathrm{O}$ is a linear molecule with four different 'isotopocules': ${ }^{14} \mathrm{~N}^{14} \mathrm{~N}^{16} \mathrm{O}(99 \%),{ }^{14} \mathrm{~N}^{15} \mathrm{~N}^{16} \mathrm{O}(\alpha, 0.4 \%)$, ${ }^{15} \mathbf{N}^{14} \mathrm{~N}^{16} \mathrm{O}(\beta, 0.4 \%)$ and ${ }^{14} \mathrm{~N}^{14} \mathrm{~N}^{18} \mathrm{O}(0.2 \%) . \mathrm{N}_{2} \mathrm{O}(\alpha)$ and $\mathrm{N}_{2} \mathrm{O}(\beta)$ differ only in the position of the ${ }^{15} \mathrm{~N}$ atom, and the difference in their abundance - known as site preference (SP) - can be a particularly powerful indicator for different $\mathrm{N}_{2} \mathrm{O}$ production mechanisms.

We developed a quantum cascade laser absorption spectroscopy (QCLAS)-based technique for $\mathrm{N}_{2} \mathrm{O}$ isotope measurements. QCLAS is inherently selective due to differences in fundamental rovibrational bands, even for molecules with the same mass. This technique thereby surpasses isotope ratio mass spectrometry, which does not allow for direct measurement of site-specific ${ }^{15} \mathrm{~N}$ isotopic composition. [1] QCLAS allows real-time measurement and can be coupled to preconcentration for field-deployable monitoring of ambient air.

We applied QCLAS to measure $\mathrm{N}_{2} \mathrm{O}$ isotopic composition in a number of studies, e.g., to identify $\mathrm{N}_{2} \mathrm{O}$ production pathways from a pilot-scale partial nitritation-anammox wastewater treatment system. ${ }^{[2]}$ If $\mathrm{N}_{2} \mathrm{O}$ production from these systems is minimized, wastewater treatment can be carbon-neutral. Since April 2014,

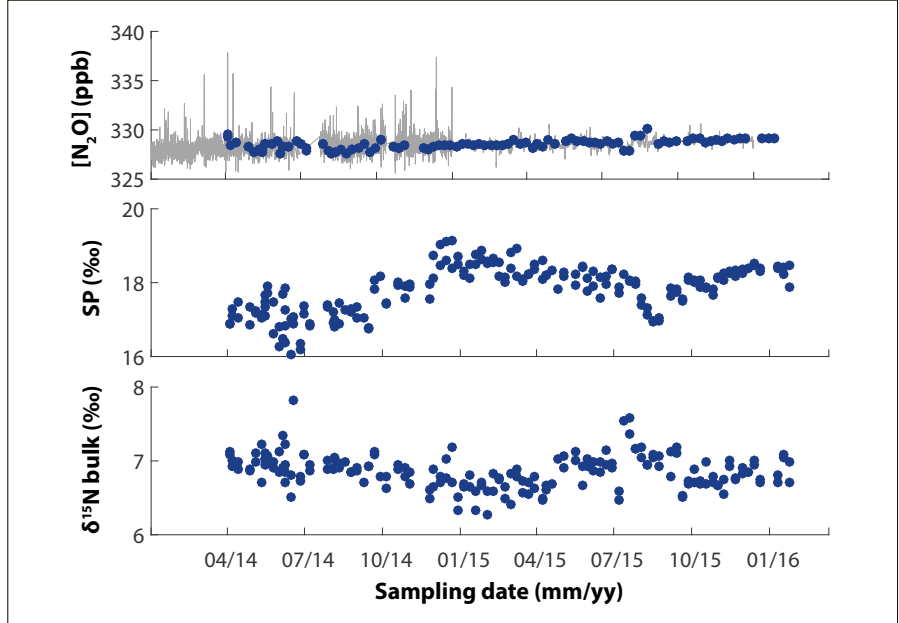

Top panel: Mole fraction of $\mathrm{N}_{2} \mathrm{O}$ at Jungfraujoch. In situ measurements using GC-ECD (2014: Agilent 6890N) and off-axis ICOS (2015-16: LGR-23r, Los Gatos Research) are shown in grey (data credit: M. Steinbacher, Empa, Global Atmospheric Watch). Flask measurements made using QCLAS (Aerodyne Research, Inc.) are in blue. Lower panels: $\mathrm{N}_{2} \mathrm{O}$ isotopic composition measured in flask samples using preconcentration coupled to QCLAS.

we have been measuring $\mathrm{N}_{2} \mathrm{O}$ isotopic composition at the high alpine site Jungfraujoch using QCLAS with preconcentration. The results show unexpectedly strong seasonal variability in site preference at this remote site, which is not captured by current models. Within an ongoing project, we plan to confirm this intraannual variability by continuing the measurements.

QCLAS offers the potential for high-precision analysis of $\mathrm{N}_{2} \mathrm{O}$ isotopic composition in a wide range of applications, to trace emission and consumption pathways.

Received: November 10, 2016

[1] J. Mohn, B. Wolf, S. Toyoda, C. T. Lin, M. C. Liang, N. Brüggemann, H. Wissel, A. E. Steiker, J. Dyckmans, L. Szwec, N. E. Ostrom, K. L. Casciotti, M. Forbes, A. Giesemann, R. Well, R. R. Doucett, C. T. Yarnes, A. R. Ridely, J. Kaiser, N. Yosida, Rapid Commun. Mass Sp. 2014, 28, 1995.

[2] E. Harris, A. Joss, L. Emmenegger, M. Kipf, B. Wolf, J. Mohn, P. Wunderlin, Water Res. 2015, 83, 258
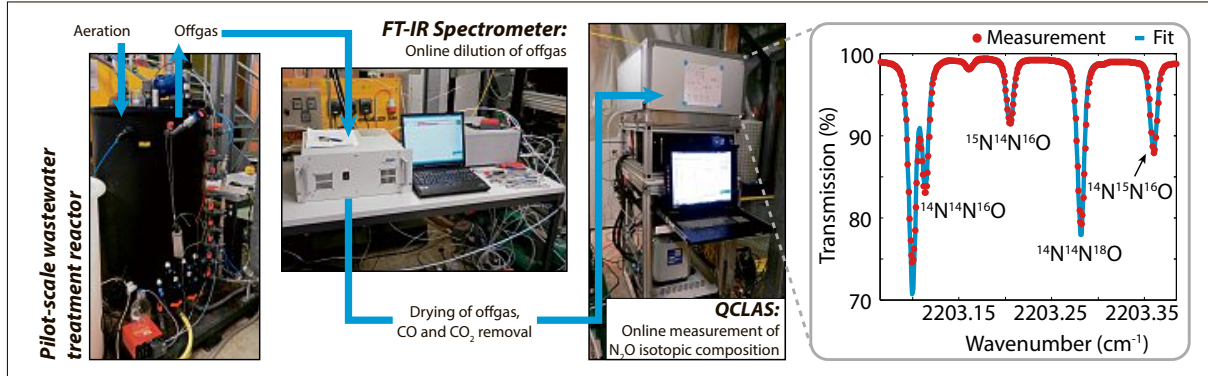

A schematic view of the analytical set-up used for online monitoring of isotopic composition in the off-gas from a pilot-scale partial nitritationanammox reactor: Offgas from the wastewater treatment reactor is diluted online, using measurements from the FT-IR to scale the dilution, before continuous measurement of isotopic composition with QCLAS. At the right hand side, an example of a QCLAS spectrum is shown, illustrating the simultaneous quantification of all four isotopocules. 